


\section{AUGE Y DECLIVE DEL MOVIMIENTO INDÍGENA ECUATORIANO [1990-2008]}

(Recepción: Marzo 25 de 2013 - Aceptación: Mayo 27 de 2013)

Edwin Cruz Rodríguez*

\section{Resumen}

Entre 1990 y 2008 el movimiento indígena ecuatoriano tuvo un alto nivel de articulación organizativa que lo llevó a desarrollar una gran capacidad de protesta, pero ello no se tradujo en reformas institucionales de envergadura en forma temprana. Cuando se producen las principales reformas, con la Constitución de 2008 que reconoce el carácter plurinacional del Estado, el movimiento ha entrado en declive y mermado su capacidad de protesta. Este artículo intenta explicar esta paradoja. El movimiento no consiguió reformas institucionales en forma temprana por una configuración particular de la estructura de oportunidades políticas (EOP): un sistema político cerrado a la participación institucional de los actores indígenas, acompañado de bajos costos para la acción colectiva en términos de represión, llevó al movimiento a privilegiar la protesta y lo alejó de posibles coaliciones con actores gubernamentales.

\section{Palabras clave}

Acción colectiva, Movimientos indígenas, Ecuador.

\section{RISE AND FALI OF INDIGENOUS MOUEMENT ECUATORIANO [1990-2008]}

\section{Albstract}

Between 1990 and 2008 the Ecuadoran indigenous movement had a high level of organizational articulation which resulted in a great capacity for protest, but this did not translate into early major institutional reforms. When the major reforms started in 2008 with the constitution that recognizes the plurinational nature of the state, the movement has gone into decline and reduced its capacity for protest. This paper attempts to explain this paradox. The movement did not obtain early institutional reforms due to a particular configuration of the structure of political opportunities (EOP): A political system that didn't allow the institutional participation of indigenous actors, together with low costs for the collective action in terms of repression, which led the movement to favor the protest and removed it from possible coalitions with governmental actors.

\section{Kevwords}

Collective action, Indigenous movements, Ecuador.

1 Artículo de Investigación

* Candidato a Doctor en Estudios Políticos y Relaciones internacionales e integrante del Grupo de Investigación en Teoría Política Contemporánea de la Universidad Nacional de Colombia. ecruzr@unal.edu.co 


\section{Introducción}

Entre 1990 y 2008 la arena política ecuatoriana fue sacudida por el movimiento indígena. El Levantamiento indígena en junio de 1990, abrió un ciclo de luchas cuya más importante conquista fue el reconocimiento del Estado plurinacional en la nueva Constitución (2008). Aunque en Ecuador la población que se auto-identifica como indígena es minoritaria ${ }^{2}$, el movimiento alcanzó un alto grado de organización y coordinación y no tuvo parangón con ningún otro en América Latina en cuanto al número e intensidad de las acciones colectivas contestatarias (Bretón, 2003, p. 250; Yashar, 2005, p.85). Sin embargo, desde el punto de vista del impacto institucional, su intensa actividad no se tradujo en forma temprana en reformas estatales orientadas al reconocimiento de los derechos colectivos (Sánchez, 1996, p.114-115).

En países como Bolivia la ratificación del Convenio 169 de la OIT, que reconoce los derechos de los pueblos indígenas, se produjo sin un alto grado de conflictividad en 1991, y en 1994 se implementó una reforma constitucional para reconocer derechos colectivos a los pueblos. En contraste, en Ecuador tanto la ratificación del Convenio como las reformas constitucionales para el reconocimiento de derechos colectivos se desarrollaron con un alto grado de conflictividad y sólo serían posibles en 1998. Incluso, el último proceso constituyente (2007), aunque amplió el rango de derechos reconocido e insertó elementos de la cosmovisión indígena en la Constitución, dejó un sinsabor en el movimiento, pues como afirma Moreano (2006), a diferencia

2 En el censo de 2001, el 6,1\% de la población de 15 años o más se auto-clasificó como indígena, el $77,7 \%$ como mestiza y el $10,8 \%$ como blanca. Este dato tendió a confirmarse en el censo del 28 de noviembre de 2010 , en el que el $7 \%$ de los ecuatorianos se auto-clasificaron como indígenas, el 7.2 como afro descendientes y el $55 \%$ como mestizos. de Bolivia, en Ecuador no fueron los indígenas los que impusieron los temas de la agenda pública.

Durante buena parte del período estudiado, el movimiento indígena ecuatoriano privilegió un repertorio de acción disruptiva y ascendió en sus dinámicas de acción colectiva. Realizó grandes protestas, denominadas con frecuencia "levantamientos indígenas", en 1990, 1992, 1993, 1994, 1999, 2000 y 2001. Fue protagónico en la destitución de dos presidentes, A. Bucaram en febrero de 1997 y Jamil Mahuad en enero de 2000. Paradójicamente, el movimiento perdió su capacidad movilizadora luego de su participación en el gobierno de Lucio Gutiérrez (2003).

¿Por qué el alto nivel de articulación organizativa y la gran capacidad de protesta del movimiento indígena no se tradujeron en reformas institucionales de envergadura en forma temprana? ¿Qué explica el hecho de que el movimiento entrara en declive justo en el momento en que su repertorio cambia, de la protesta hacia la participación institucional?

Este artículo estudia las dinámicas de acción colectiva del movimiento indígena en Ecuador para responder estas preguntas acudiendo a la "agenda clásica" para el estudio de los movimientos sociales (McAdam, Tarrow y Tilly, 2005, p. 45; McAdam, McCarthy y Zald, 1999; Tarrow, 1997). Sostiene que el movimiento indígena ecuatoriano consiguió una gran articulación organizativa mediante la Confederación de Nacionalidades Indígenas del Ecuador (CONAIE) que aglutina organizaciones de la Sierra, la Amazonía y la Costa, y un proceso de enmarcado eficaz al articular sus demandas en el marco del Estado plurinacional. Sin embargo, no consiguió reformas institucionales en forma temprana por una configuración particular de la estructura de oportunidades 
políticas (EOP): un sistema político cerrado a la participación institucional de los actores indígenas, acompañado de bajos costos para la acción colectiva en términos de represión, llevó al movimiento a privilegiar la protesta y lo alejó de posibles coaliciones con actores gubernamentales. Lo paradójico del caso es que justo cuando el movimiento cambia su repertorio disruptivo por la participación institucional y encuentra aliados influyentes en el gobierno de Gutiérrez, empieza su declive.

Para desarrollar este argumento, el trabajo se estructura en cuatro partes. Primero, considera las estructuras de movilización y destaca la articulación organizativa del movimiento. Segundo, analiza el proceso de enmarcado basado en la reivindicación del Estado plurinacional. En tercer lugar, examina la estructura de oportunidad política que explica el auge del movimiento. Finalmente, estudia las interacciones entre esas variables y propone explicaciones para las preguntas planteadas.

\section{La articulación orgánica de la CONAIE}

Las estructuras de movilización son las formas organizativas que hacen posible la acción colectiva, como afirman McAdam et al. (1999, p.25), “los canales colectivos tanto formales como informales, a través de los cuales la gente puede movilizarse e implicarse en la acción colectiva". Designa redes de relaciones públicas y privadas, incluso aquellas que no tienen como objetivo principal generar la movilización, pero que pueden sustentarla en un momento dado, como las redes de amigos, familia, trabajo y estudio, entre otras. (McCarthy, 1999, p.206). En Ecuador las estructuras de movilización básicas son las comunidades indígenas, que han adoptado distintas formas de acuerdo a la región donde operan y a los apoyos que reciben, iglesias, ONG.
En la Amazonía ecuatoriana hasta los años sesenta el Estado delegó la administración a elites locales y misiones religiosas (Chiriboga, 1986, p.80). En la ley de reforma agraria y colonización de 1964, la región fue considerada como un territorio baldío. Las poblaciones indígenas se organizaron tempranamente con el apoyo de la Iglesia. En 1961 arrancó el proceso con un curso para la formación de dirigentes ofrecido por la misión salesiana. La Federación de Centros Shuar se organizó por la presión de colonos sobre sus tierras, la formación de poblados Shuar de tipo no tradicional entre los 50 y 60 y el crecimiento de los Shuar bilingües, y en 1954 obtuvo personería jurídica (Gnerre y Bottasso, 1986, p.18). Con posterioridad emergieron otros procesos organizativos de base comunitaria entre los que cabe mencionar el de la Organización de Pueblos Indígenas del Pastaza (OPIP) que tuvo un papel muy importante en la demanda por territorio en los años noventa.

Según McCarthly (1999, p.215), hay una disponibilidad de formas organizativas en cada cultura sobre la que los movimientos adaptan, innovan e inventan. En Ecuador, de acuerdo con Korovkin (2002, pp.2021), con la reforma agraria de 1964 los huasipungueros de la Sierra perdieron su lucha por la tierra, pero fue una victoria "político organizativa" porque generó un proceso en el cual grupos indígenas empezaron a acogerse a la Ley de Comunas de 1937. Constituidos en comunas, estos grupos restablecieron sus vínculos de vida comunitarios que en muchos lugares habían sido prácticamente disueltos por el régimen de hacienda. Como sostiene Figueroa (1996, p.192), ello implicó una apropiación de la categoría de "comunidad" y el inicio del proceso de formación de una identidad propia. Las comunidades con personería jurídica accedían a mecanismos de 
"autogobierno" con capacidad de representación y gestión de recursos, necesarios para emprender luchas por la tierra o protegerse del asedio de terratenientes. Así, se produjo una reinvención de las comunidades.

Desde la perspectiva de las estructuras de movilización, la intensidad y constancia en las acciones colectivas del movimiento indígena ecuatoriano se explican por una alta articulación organizativa que permitió una coordinación con acciones de amplio alcance. Las organizaciones indígenas emprendieron procesos hacia la unidad a nivel nacional, a fines de los 70 y principios de los 80, con la formación del Consejo de Coordinación de las Nacionalidades Indígenas del Ecuador (CONACNIE), en 1981. El proceso de unificación daría frutos con la conformación de la Confederación de Nacionalidades Indígenas del Ecuador (CONAIE) en 1986.

De forma que el movimiento indígena ecuatoriano logró una articulación estable alrededor de la CONAIE, que agrupó la organización indígena de la Sierra, Ecuador Runacunapac Riccharimui- Despertar del pueblo indio (ECUARUNARI), y la de la Amazonía, Confederación de Nacionalidades Indígenas de la Amazonía Ecuatoriana (CONFENAIE) (CONAIE, 1989, p.223). Aunque la CONAIE no es la única organización indígena nacional, desde el levantamiento de 1990 se constituyó en la coordinadora de las acciones colectivas del movimiento y en la principal articuladora a nivel discursivo con su propuesta de Estado plurinacional $^{3}$. Es la organización más radical, se proclama representante de

3 Hay otras organizaciones nacionales, con menor alcance geográfico y modos de organización y participación distintos, como la Federación Ecuatoriana de Indios (FEI), la Federación Ecuatoriana de Nacionalidades y Organizaciones Campesinas, Indígenas y Negras (FENOCIN) adscrita al Partido Socialista, y la Federación de Indígenas Evangélicos del Ecuador (FEINE) con ayuda de Iglesias norteamericanas, las cuales tienen agendas y formas de acción distintas que a veces rivalizan con las de la CONAIE (Dávalos, 2005, 280) pueblos y nacionalidades indígenas y su base amplia4.

Pese a su alto nivel de coordinación, en el interior del movimiento ecuatoriano hubo tensiones ${ }^{5}$. No obstante, estas tensiones no lo desarticularon. Ello puede explicarse en parte por la forma como se solucionaron: conciliando las posiciones en conflicto, como sucedió con la articulación de clase y etnia en la plataforma política o cuando se decidió participar institucionalmente en la Constituyente de 1997 y simultáneamente hacer una asamblea alternativa para disputar la legitimidad institucional ${ }^{6}$.

4 Aglutina las tres regiones (Sierra, Costa y Amazonía). A su interior, las organizaciones miembros han definido autónomamente la forma de organización, de tal manera que se encuentran centros, federaciones y cooperativas (Massal, 2000, p.168). La unidad organizativa básica del movimiento es la comunidad. Sus poblaciones están asentadas en un territorio delimitado con fuerte sentido de pertenencia, representación propia, fuertes lazos de parentesco y en algunos casos formas de propiedad comunitaria. La organización comunal no solo está vigente en zonas de predominio indígena, sino también en zonas mestizas. Sin embargo, se han modificado algunas de sus características tradicionales. Una tendencia importante en los 90 es hacia el crecimiento de las asociaciones y la diversificación de formas de organización rural, muchas agrupadas en organizaciones de segundo grado de carácter provincial o nacional, que si bien estaban presentes desde antes, tomaron fuerza con los proyectos de desarrollo con financiación internacional (Guerrero y Ospina, 2003, p.137)

5 Por ejemplo, entre las organizaciones de la Sierra y la Amazonía, existen formas distintas de entender la plurinacionalidad. De acuerdo con Barrera (2001, p. 191) existieron dos lecturas: la amazónica, que enfatizó en la necesidad de jurisdicciones de territorios autónomos, aprovechando que en esa región había continuidad en los asentamientos indígenas; y la serrana, que hizo énfasis en el fortalecimiento de la autoridad comunal y el respeto a sus formas organizativas y culturales, cuyos representantes no estuvieron tan convencidos de la necesidad de jurisdicciones autónomas. Segundo, aunque el discurso del movimiento articuló lo étnico con las reivindicaciones de clase, los indígenas amazónicos privilegiaron lo étnico-cultural, dado que no pasaron por las luchas de recuperación de la tierra de los pueblos serranos ni tuvieron las mismas influencias de la izquierda (Barrera, 2001, p.193). Tercero, tanto en el interior de la CONAIE como en el Movimiento de Unidad Plurinacional Pachakutik Nuevo País (MUPP $\mathrm{NP})$, movimiento político de indígenas y otros sectores sociales fundado en 1996 para participar en elecciones, persistió una tensión entre los que privilegiaron la lucha por demandas indígenas exclusivamente y quienes propugnaron por articular sectores y demandas más diversos. Finalmente, tensiones originadas por la cooptación de sectores del movimiento por parte de los gobiernos en varias coyunturas y por disputas personalistas.

6 Ante la convocatoria de Asamblea Constituyente por el gobierno interino de Fabián Alarcón, en 1997, el movimiento se planteó como opciones no participar y realizar una asamblea alternativa, posición inicialmente adoptada por la CONAIE, o participar, 
Además, lo que permitió mantener el movimiento articulado fue el acuerdo básico en el los marcos de su acción colectiva, articulados en el proyecto de construcción del Estado plurinacional.

\section{El Estado plurinacional: un marco eficaz}

Los marcos de acción colectiva son "esquemas interpretativos" mediante los cuales los participantes en un movimiento social conciben y explican el mundo (Snow y Benford, 1992, p.137). Su objetivo es "forjar formas compartidas de considerar el mundo y a sí mismos que legitimen y muevan a la acción colectiva" (McAdam et al., 1999, p. 27). El concepto resalta el papel activo de los actores pues "tanto la cultura como el proceso enmarcador de ideas se conciben estratégicamente" (Zald, 1999, p.369). Los procesos de enmarcado implican un conflicto, tanto en el interior del movimiento como en relación con sus adversarios, entre distintas visiones del mundo, formas de explicar los problemas, soluciones y cursos de acción (Zald, 1999, p.370). Los marcos tienen tres elementos básicos: (1) el diagnóstico de la realidad, por qué las cosas no son como deberían ser, (2) la identidad, o la autodefinición de un "nosotros", que están de acuerdo con (3) una solución a los problemas, un deber ser en función del cual se produce la acción colectiva. La intensidad y constancia en la acción colectiva del movimiento indígena ecuatoriano pueden explicarse por la efectividad de su marco.

La coordinación de la CONAIE se tradujo en una mayor articulación discursiva con el proyecto de Estado plurinacional, en la medida en que todos los sectores articulan sus demandas apelando a la construcción de este tipo de Estado,

posición mayoritaria en Pachakutik. Al final las dos conciliaron y se hicieron ambas cosas (Barrera, 2001, p.239). El proceso de la constituyente alternativa implicó una movilización de los indígenas por todo el país debatiendo sus tesis. de tal forma que no hay reclamaciones que no puedan englobarse en esta reivindicación. Esto le permitió llevar a cabo acciones de mayor envergadura y con mayor regularidad al contar con un claro objetivo de largo plazo.

En el marco del movimiento el diagnóstico del problema está marcado por la persistencia del colonialismo, como un eje articulador de la sociedad y el Estado ecuatorianos, que conlleva la exclusión, opresión y explotación de los indígenas ${ }^{7}$. En este sentido, para el movimiento la República no acabó con el colonialismo, por el contrario, persistió en el despojo y la corrupción que acabó con el armónico y civilizado orden precolonial. Se trata de una concepción esencialista en la cual a "occidente", la sociedad nacional englobante blanca o mestiza, le atribuyen valores negativos como el individualismo, la violencia, la corrupción y la degradación moral, mientras a sí mismos se atribuyen valores como la solidaridad, la armonía, la nobleza, la justicia y el trabajo (Almeida, 1995, p.16). Pero es un "esencialismo estratégico", una definición con fines políticos que pretende realzar el impacto del discurso del movimiento (Korovkin, 2002, p.132).

El "nosotros" en el marco del movimiento está concebido en términos de la auto-identificación que el movimiento hace de los indígenas como pueblos y nacionalidades. Con estos significantes su discurso cuestiona las representaciones negativas y racializadas con las que habían sido concebidos como salvajes

7 El documento de la historia "oficial" de la CONAIE afirma: “(...) los pueblos indios nos hemos unido a partir, en primer lugar, del reconocimiento de nuestra heterogeneidad así como de los rasgos culturales semejantes; de la convicción de ser partícipes de una misma historia de opresión y explotación; y, de que también somos parte de una sociedad más amplia en la cual estamos cuestionando la naturaleza de un estado nacional que no reconoce nuestras identidades culturales diferentes por lo que es un problema que debe ser resuelto" (CONAIE, 1989, pp. 268-169). Si bien aquí citamos los documentos fundacionales de los movimientos, estos discursos son persistentes en sus acciones colectivas y en coyunturas críticas hasta la actualidad. 
e incivilizados (Ibarra, 1999, p.77) y plantea una definición propia de su identidad, desafiando la identificación como "campesino" impuesta por las políticas estatales. Existe un consenso en el movimiento indígena sobre los términos que delimitan su identidad. El uso de la categoría de "nacionalidades indígenas" ha tenido un fuerte contenido estratégico. Como sostuvo la líder de la CONAIE Blanca Chancoso (1993, pp.136-137), los dirigentes afirmaron la categoría de "nacionalidades" en contra de la de "etnias", porque consideraban que esta era una denominación externa al movimiento que los ubicaba como minorías y como un problema, a su juicio, menos relevante para el Estado.

Además, ese "nosotros" que construye el movimiento no se agota en los indígenas, sino que trata de articular otros actores a sus luchas a partir de la definición de objetivos y enemigos comunes. Durante los años setenta hubo una discusión respecto a la base social de ECUARUNARI. Para algunos se trataba de forjar un movimiento exclusivamente indígena. Otros, sostenían la necesidad de articularse a luchas de sectores no indígenas. Al final, triunfó la segunda perspectiva pero en el discurso se presentaron como alternativas complementarias (Ibarra, 1992, p.145). Más tarde, el movimiento afirmaría tener dos problemas, "como miembros de una clase y como parte de diferentes nacionalidades indígenas (...)." (CONAIE, 1989, p.261). El principal adversario en la perspectiva del movimiento ecuatoriano es "Estado uninacional burgués", que articula la dominación colonial, la discriminación racial y la explotación. La transformación de esa forma de Estado pasa por la articulación con otros sectores: "nos planteamos la unidad de todos los sectores populares para la transformación estructural de la sociedad y la instauración de una sociedad igualitaria, justa y pluricultural, representada en un Estado plurinacional" (CONAIE, 1989, p.269)

Finalmente, el proyecto que articula el marco de acción colectiva está estructurado alrededor del "marco maestro" del concepto de Estado plurinacional $^{8}$. Las distintas organizaciones agrupadas en la CONAIE enmarcaron sus demandas en el proyecto del Estado plurinacional. No hubo discursos que reivindicaran la autodeterminación de nacionalidades indígenas y ello hizo posible conciliar con mayor facilidad. Los adversarios del movimiento en varios momentos se opusieron al Estado plurinacional argumentando que suponía la fragmentación del Estado nación. Pero las organizaciones y líderes indígenas se esforzaron por precisar sus concepciones de plurinacionalidad y autonomía territorial, con el fin de mostrar que no necesariamente eran contrarios a la existencia de un estado unitario'. Sin embargo, dicho proyecto también planteaba transformaciones estructurales necesarias para cambiar las formas de integración del indio y el reconocimiento de la diversidad de la nación. Desde el Proyecto Político de la CONAIE, en 1994, el Estado plurinacional no se planteó sólo como solución al "problema indio", sino como una reestructuración global que beneficiaría otros sectores (Barrera, 2001, p.189). No sólo concilia la diversidad existente en el interior del país, también supone cambios en el sistema político y en el modelo de desarrollo económico,

8 Snow y Benford (1992, p.246) plantean que un marco maestro es aquel que se usa para movilizar un "sector" de movimientos, como el marco de "derechos" o el de "autonomía". Ello implica cierta "modularidad" en el marco, es decir, su capacidad para ser usado por distintos actores en distintos contextos (Tarrow, 1997, p.69).

9 En palabras de la dirigente de la CONAIE, Blanca Chancoso, "nuestros reclamos no hacen referencia a un espacio único, no radica nuestra aspiración en la creación de reservas indígenas; cuando exigimos nuestro derecho a la territorialidad, pedimos que se reconozcan las tierras para nuestros pueblos y lo hacemos en la esfera del país, pues no nos interesa solamente agruparnos entre indígenas y aislarnos" (Chancoso, 2000, p.57) 
tal como lo expuso el cofundador de la CONAIE Luis Macas ${ }^{10}$.

La reivindicación del Estado plurinacional se planteó como contraria al neoliberalismo. Esto le permitió al movimiento articularse con diversos sectores igualmente opuestos, planteando su lucha como una lucha nacional y no sólo por sus intereses sectoriales. Así, podría decirse que el marco del movimiento ecuatoriano no sólo fue exitoso en articular a los sectores del movimiento, sino incluso a actores externos. De acuerdo con Guerrero y Ospina (2003, p.167), la lucha contra la implementación de las reformas neoliberales, entre 1992 - 1996, y entre 2000 - 2002, permitió a la CONAIE establecer alianzas con actores no indígenas, definir su identidad en contraposición a los sectores que apoyaron este tipo de las políticas y plantear un proyecto incluyente y no sólo por los intereses indígenas.

\section{Explicando el auge del movimiento}

El concepto de EOP hace referencia a dimensiones del entorno político que fomentan o desincentivan la acción colectiva. Esta definición parece bastante "estructuralista", dado que supone que las oportunidades son factores objetivos del contexto. Sin embargo, Tarrow ha llamado la atención sobre el proceso

10 "Cuando nosotros hablamos aquí en nuestro país de la construcción de un Estado Plurinacional: ¿Qué es lo que sugerimos? ¿Qué es lo que decimos? Fundamentalmente, es necesario comprender que no solamente se trata de un discurso para justificar la diversidad. Lo diverso está allí y siempre ha estado allí (...). En primer lugar una reformulación de la democracia. Una democracia no solamente representativa, sino una democracia participativa, comunitaria; una democracia mucho más amplia, basada en el diálogo, en el consenso, en la revocatoria y la fiscalización permanentes. Hablamos de la profundización de esa democracia con el contingente de otros pueblos, y por eso es importante esa diversidad para poder hacer que en este país se exprese la existencia del Otro (...). El Estado plurinacional es también la reforma del sistema económico, es la eliminación de la explotación, es la incorporación de unas racionalidades a la racionalidad económica imperante actualmente y que amenaza con la destrucción física de nuestro planeta" (Macas, 2005, pp.38-39) interpretativo y cognitivo que conlleva tal categoría:

Cuando hablo de oportunidad política estoy haciendo referencia a señales continuas -aunque no necesariamente permanentes, formales o a nivel nacional- percibidas por los agentes sociales o políticos que les animan o desaniman a utilizar los recursos con los que cuentan para crear movimientos sociales. Según mi concepto de la oportunidad política habría pues que considerar, no sólo las estructuras formales, como las instituciones, sino también las estructuras de alianza generadas por los conflictos, que contribuyen a la obtención de recursos y crean una red de oposición frente a constricciones o limitaciones externas al grupo. (1999, p.89).

LA EOP comprende la estructura institucional y las relaciones informales de poder de un sistema político nacional, y se usa como una variable o una serie de variables independientes para explicar el origen, la forma o incluso el impacto alcanzado por los movimientos (McAdam et al., 1999, p.23). Varios autores han tratado de delimitar las posibles variables que comprendería la EOP ${ }^{11}$.

El concepto ha sido criticado porque no sólo las oportunidades políticas tienen un efecto sobre los movimientos. Existen factores sociales y culturales que tienen incidencia en el origen, desarrollo e impactos de los movimientos. Por ello, Ruch (1999, pp.266-269) propone el concepto de "estructura de contexto" que abarcaría: el contexto cultural, las actitudes y conductas que pueden apoyar el movimiento; el contexto

11 Para Tarrow (1999, p.90), "existen cuatro tipos de indicadores importantes: la posibilidad de acceder al poder, los cambios en las alineaciones, la posibilidad de contar con aliados influyentes y las escisiones en el seno de las élites". McAdam (1999, p.5455), por su lado, sostiene que serían parte de la EOP: "1. El grado de apertura relativa del sistema político institucionalizado. 2 . La estabilidad 0 inestabilidad de las alineaciones entre élites, alineaciones que ejercen una gran influencia en el ámbito de lo político. 3. La presencia 0 ausencia de aliados entre las élites. 4. Capacidad del Estado y su propensión a la represión". 
social, el entorno que limita o facilita la construcción de identidades colectivas y la organización de los movimientos; y el contexto político, correspondiente a la EOP.

El concepto de "estructura de contexto" es pertinente para comprender procesos sociales que intervienen en la génesis de los movimientos. El origen es posible debido a cambios estructurales producto de los procesos de modernización en la segunda mitad del siglo $X X$, que erosionaron las formas tradicionales de dominación de las poblaciones indígenas, como el sistema de hacienda y el paternalismo de la Iglesia católica, posibilitando la emergencia de dirigentes indígenas que accedieron a la educación formal y encontraron en la afirmación de su identidad étnica una forma para enfrentar los cambios (Guerrero y Ospina, 2003, pp.10-11; Moreano, 1993, pp.222-224). Liberados de la hacienda y apoyados por algunas ONG de desarrollo, los indígenas accedieron a una mayor presencia en el gobierno local, pero también se enfrentaron a otras formas de opresión dado que los procesos de modernización alentaron la migración a la ciudad (Ibarra, 1999, p.79). La formación de una élite dirigente indígena tiene lugar en los 70 y 80 , y se manifiesta con fuerza en los años 90. Los dirigentes de los 60, formados en el período de la reforma agraria, tenían origen campesino, poca educación formal y poco contacto con el mundo urbano. El "dirigente migrante urbano" de los 90, con estudios formales, "ha creado sus comunidades en su imaginación", no pretende la integración sino la diferenciación (Bengoa: 2000, pp.82-83).

McAdam (1999, pp. 62-64) Ilama la atención sobre la necesidad de contemplar el contexto internacional dentro de la EOP. El fin de la guerra fría posibilitó la emergencia de discursos distintos a su dicotomía y una "internacionalización" de la cuestión indígena, con preocupaciones como el medio ambiente, los derechos humanos y el desarrollo sostenible o etno-desarrollo (Gros, 1999, p.8). Los organismos internacionales de desarrollo (Banco Mundial, BID, PNUD) incorporaron en sus agendas el tema indígena y crearon instancias especializadas (García, 2003, p.199). Articulado con las políticas ambientales, el indígena se valoró como protector "natural" del medio ambiente (Gros, 2000, p.358). Finalmente, la afirmación internacional de los derechos de las minorías posibilita el reclamo a los Estados el reconocimiento de derechos (Moreno y Figueroa, 1992, p. 39).

Pero las oportunidades más influyentes se encuentran en el contexto nacional de democratización, desde fines de los años 60, y agotamiento del modelo de desarrollo centrado en el Estado, para transitar al modelo de mercado libre en los 90.

Los cambios en la orientación de la acción estatal inciden en el desarrollo de los movimientos indígenas al menos en tres sentidos. Primero, las políticas asimilacionistas del período populista desarrollista entran en crisis con el modelo de desarrollo (Iglesias y Espasandín, 2007, p.59). Ello libera los indígenas de presiones hacia la asimilación al proyecto de nación mestiza y abre un espacio para plantear proyectos propios. Segundo, el retiro de las políticas del Estado interventor produce descontentos, sobre todo en el contexto de crisis económica de los 80 que afecta críticamente el sector agrario, los cuales presionan la politización de las comunidades indígenas. Tercero, las políticas de discriminación positiva y focalización del Estado neoliberal proporcionan un entorno benéfico para identificarse como indígenas (Bengoa, 2000, p.68). Las nuevas políticas interpelan a las comunidades con la descentralización 
político administrativa y la democracia participativa (Gros, 1999, p.10).

El vacío producido en el campo popular como consecuencia de la crisis de las organizaciones y discursos de izquierda, permitió el ascenso de las organizaciones indígenas al escenario nacional. EI debilitamiento del movimiento sindical causado por la desindustrialización y la flexibilización laboral fue a la par con la emergencia de otros actores, entre ellos el movimiento indígena. La irrupción del movimiento llenó un vacío en la izquierda luego de la caída del muro de Berlín (Barrera, 2001, p.151). Ello explica su rápido reconocimiento como representante de sectores indígenas y campesinos, entre otros. Además, la apertura de las organizaciones indígenas respecto a demandas de sectores sociales no reivindicadas por la izquierda tradicional, feministas, ambientalistas y clases medias, le abrió un campo de apoyos importante (León, 1994, pp.106107).

La emergencia de los movimientos en los 90 coincide con un cambio sustancial en las orientaciones del Estado que lo llevan a reconocer la diversidad y abanderar políticas multiculturalitas. El presidente Borja (1988-1992) se refirió a los indígenas como "nacionalidades", gestionó medidas para reconocer sus derechos, como la Dirección Nacional de Educación Intercultural Bilingüe, y le asignó un apartado a la cuestión indígena en su plan de gobierno (Almeida, 1993, pp.13-14). Aunque estas apreciaciones cambiaran entre gobiernos, las políticas estatales se orientaron al reconocimiento de derechos y la integración de los indígenas e incluso propiciaron su participación en la administración pública y la gestión de proyectos de desarrollo de acuerdo a los principios de descentralización y participación ciudadana.
En fin, al examinar la EOP encontramos que los movimientos son catalizados por cambios estructurales profundos operados en la segunda mitad del siglo $X X$, por un contexto internacional favorable y por las oportunidades que brindaron los procesos de transición a la democracia y reforma del Estado. El país tuvo un modelo de Estado abierto a la cuestión indígena en los años 90.

\section{Las dinámicas de la acción colectiva}

Del análisis hecho hasta este punto se desprende que la intensidad y constancia de la acción colectiva se explican por una mayor articulación organizativa y discursiva en el movimiento indígena ecuatoriano.

No obstante, estas explicaciones sólo pueden ser parciales. Una explicación más comprensiva de los problemas planteados debe tener en cuenta la forma como estas variables han entrado en interacción en el proceso político del movimiento. Como sostienen McAdam et al. (1999, pp.26-29) las tres variables por separado son necesarias pero no suficientes para explicar las dinámicas de la acción colectiva, es necesario examinar la interacción entre ellas para entender cómo cambian en el tiempo. Este análisis permitirá responder por qué, pese a que el movimiento ecuatoriano tuvo acciones de mayor alcance y más persistentes durante el período, no consiguió tempranamente reformas de reconocimiento de derechos colectivos por parte del Estado, y cómo se explican los distintos ritmos de la acción colectiva. Las EOP cambian con el tiempo de acuerdo a las relaciones entre los distintos actores y tienen un efecto sobre las estructuras de movilización y los marcos de acción colectiva. En el mismo sentido, es posible que distintas formas de organización y procesos de enmarcado sean más eficaces para 
el aprovechamiento de determinadas oportunidades.

Según McAdam et al.(1999, p.33), la EOP y los cambios que en ella se operen pueden llegar a determinar la forma de la acción colectiva (movilización, lobbies, elecciones, violencia y demás). En el mismo sentido, para Ruch (1999, p.271), la estructura del movimiento tiende a ser más formal (partido, grupo de interés), cuando más apertura en el sistema de partidos y en los mecanismos de toma de decisiones políticas exista. En Ecuador un sistema político cerrado a la participación institucional de los actores indígenas, acompañado de bajos costos para la acción colectiva en términos de represión, llevó al movimiento a privilegiar la protesta y lo alejó de posibles coaliciones con actores gubernamentales. Ello explicaría su dificultad para encontrar aliados institucionales para desarrollar reformas en forma temprana.

Aunque la Constitución de 1979, que sentó las bases de la transición a la democracia, reconoció el derecho al sufragio a la población indígena, el sistema de partidos, la "partidocracia", continuó cerrado a la participación de tales actores (Freidenberg y Alcántara, 2001). Por ello, el movimiento indígena privilegió la acción de protesta y sólo participaría en la política electoral a partir de 1996. Esto también se explica por un cambio en la EOP, pues la decisión de participar en elecciones está vinculada a la apertura del sistema de partidos luego de la reforma política que posibilitó que ciudadanos pudieran presentarse a cargos de elección popular sin necesidad de contar con el respaldo de un partido. En enero de 1996, la CONAIE realizó un congreso extraordinario en el que se decidió participar en las elecciones sin convertirse en partido. En febrero se constituyó el Movimiento de Unidad
Plurinacional Pachakutik Nuevo País (MUPP NP) que agrupó la CONAIE, la Coordinadora de Movimientos Sociales, los trabajadores petroleros y el Movimiento de Ciudadanos por un Nuevo País, y auspició la candidatura de Freddy Ehlers a la presidencia, junto con el dirigente indígena Luis Macas (Freidenberg y Alcántara, 2001, p.140).

Por otro lado, es bien sabido que el nivel de represión tiene gran incidencia en la forma que adoptan los repertorios de acción (Della, 1999, p.102). McAdam (1999, p.58) sugiere que cuando disminuye la capacidad de represión estatal de la protesta es más factible que emerjan movimientos poco institucionalizados. Este aspecto también contribuye a explicar la diferencia en los ritmos e impactos de la acción colectiva indígena si se tiene en cuenta que en Ecuador los costos de la movilización no son elevados. El movimiento, si bien no tuvo oportunidad de participación institucional, se enfrentó a bajos niveles de represión, lo cual lo condujo a orientar su acción colectiva hacia la protesta.

Según León (2005, p.26), en Ecuador la protesta para el movimiento indígena es facilitada por los bajos índices de represión gracias a la tácita alianza indígena-militar, que no obedece tanto a cuestiones coyunturales como a los antecedentes históricos de los 60 y 70, cuando los indígenas se constituyeron en un sector privilegiado por las políticas de los regímenes militares que los consideraban como el sustento de la nación. Además, los indígenas no han dejado de percibirse como una minoría, que en el discurso gubernamental debía asimilarse a la cultura mayoritaria, y los considera incapaces de llevar a cabo acciones por sí mismos. Por eso la principal reacción de las élites frente al levantamiento de 1990 no fue la represión 
desmedida sino la denuncia de que los indígenas habían sido manipulados ${ }^{12}$.

El repertorio de acción del movimiento, centrado en la protesta de gran alcance, hizo más difícil conseguir aliados en la arena institucional. Una reforma constitucional, en enero de 1996, permitió el reconocimiento del Ecuador como un país pluricultural (Beck y Mijeski, 2000, p.122). Pero asuntos como la ratificación del Convenio 169 de la OIT requerirían intensas gestiones parlamentarias por parte del Movimiento Pachakutik y sólo se conseguirían en 1998 (Massal, 2000, p.173). Además, si bien ese mismo año tendría lugar una reforma constitucional que reconocería amplios derechos colectivos a los indígenas ${ }^{13}$, este proceso tuvo lugar en una coyuntura muy particular, bajo el gobierno interino de Fabián Alarcón, luego de la forzada destitución de Abdalá Bucaram por una masiva protesta a la que se vinculó el movimiento indígena, en febrero de 1997.

Finalmente, la EOP supone un proceso que cambia por la acción agregada de los distintos actores (Tarrow, 1999, p.91). Los cambios en la EOP permiten explicar por qué empieza a declinar la capacidad de protesta del movimiento indígena ecuatoriano luego de participar en el gobierno de Lucio Gutiérrez (2003).

Este fue un período de retroceso para el movimiento ecuatoriano. El 21 de enero de 2000 , después de una crisis económica, un grupo de indígenas y oficiales rebeldes se tomó el Congreso e integró una Junta de Salvación Nacional

\footnotetext{
12 Luego del levantamiento de 1990 el presidente Rodrigo Borja afirmó el 7 de junio en el diario La Hora: “(...) cuanto más necesitamos la unidad nacional, agitadores irresponsables están manipulando a los indígenas de la Sierra, para que cometan actos de violencia que conspiran contra el avance económico del Ecuador, y sobre todo contra la provisión de alimentos para las ciudades del país" (León, 1994, p. 32-33)

13 Entre otras cosas, la Constitución de 1998 en su Artículo 1 declaró el Estado como unitario, pluricultural y pluriétnico, el castellano como el idioma oficial, el quichua, el shuar y otros idiomas ancestrales de uso oficial para los pueblos indígenas.
}

compuesta por el Coronel Lucio Gutiérrez, el presidente de la CONAIE, Antonio Vargas, y el ex presidente de la Corte Suprema de Justicia, Carlos Solórzano, con el objetivo de hacer dimitir al presidente Jamil Mahuad. Horas más tarde, el jefe del Comando Conjunto de las Fuerzas Armadas, General Carlos Mendoza, negoció su ingreso a la Junta en reemplazo de Gutiérrez y en la madrugada promovió la asunción a la presidencia del vicepresidente Gustavo Noboa, lo que el movimiento interpretó como una "traición". Estos hechos provocaron grandes contradicciones en el interior del movimiento, principalmente entre quienes criticaron el afán de tomar el poder cuando el objetivo había sido construirlo "desde abajo" (Barrera, 2000, p.14). Sin embargo, en el 2002 Pachakutik decidió no participar en las elecciones con un candidato propio y aliarse con el Partido Sociedad Patriótica (PSP) avalando la candidatura presidencial de Lucio Gutiérrez. La alianza ascendió al poder con el $54 \%$ de los votos en segunda vuelta, pero una vez en el gobierno sus relaciones se deterioraron. Esta experiencia en el poder reportó al movimiento más costos que beneficios. Gutiérrez se acercó a Washington y a la derecha del Partido Social Cristiano (PSC) mayoritario en el Congreso, negoció con el FMI, alzó los precios de los servicios públicos y apoyó el Plan Colombia. El Pachakutik legitimó indirectamente medidas que antes había rechazado y la CONAIE deslegitimó la protesta, sus dirigentes hicieron peticiones públicas a la gente para que no protestara (León, 2005, pp.21-22). La alianza se prolongó entre el 15 de enero y el 6 de agosto de 2003. El movimiento salió del gobierno deslegitimado frente a sus bases y los demás sectores que lo habían apoyado, y eso terminaría por minar su capacidad de movilización. 
El 20 de abril de 2005 tuvo lugar la "rebelión de los forajidos", protesta que condujo a la salida de Gutiérrez del poder. Sus protagonistas fueron predominantemente clases medias descontentas con la corrupción del ejecutivo, el legislativo y los partidos (Acosta, 2005). Según Massal (2006, pp.136-137) la ausencia del movimiento indígena en esta protesta se explica porque, mientras estuvo en el gobierno, la CONAIE perdió contacto con sus bases campesinas, se profundizaron las diferencias con la FENOCIN y la FEINE, se disolvió la alianza con actores no indígenas y los movimientos sociales urbanos criticaron duramente a la CONAIE por hacer parte del gobierno de Gutiérrez. Todo ello explica porque cuando la CONAIE convocó a movilizaciones no fue acatada en breve tiempo como en coyunturas anteriores.

En las elecciones presidenciales de octubre de 2006 el candidato presidencial avalado por las organizaciones del movimiento, Luis Macas, obtuvo el $2,19 \%$ de los votos. Empero, la CONAIE celebró el triunfo electoral de Rafael Correa, candidato del Movimiento Alianza País, en segunda vuelta, con el cual compartía la iniciativa de convocar una "Asamblea Plurinacional Constituyente", propuesta que había tomado fuerza desde la destitución de Lucio Gutiérrez. Correa asistió a una ceremonia de posesión orientada por sacerdotes indígenas. De esa forma, el movimiento indígena se articularía pasajeramente al proceso denominado "revolución ciudadana", pues más tarde, ya en el debate constitucional, decidió quitarle su apoyo al gobierno por haber resultado menos progresista de lo que los indígenas imaginaban. Ello explica el "sí crítico" de la CONAIE frente al referéndum que ratificó la Constitución en octubre de 2008. Para esta organización, la Constitución no implicó un cambio significativo en relación con las disposiciones consagradas en 1998. Marlon Santi, presidente de la CONAIE, explicó el "sí crítico" porque aunque el texto reconoció las categorías de nacionalidades, su estructura política y administrativa, ello no se expresó en autonomía.

\section{Conclusión}

La mayor intensidad y constancia en la acción de protesta del movimiento indígena ecuatoriano se explica por las características de su articulación organizativa y por la eficacia de su proceso de enmarcado. La CONAIE consiguió articular procesos organizativos de distintas regiones y orientarlas en un proyecto común: el Estado plurinacional. Ello aseguró importantes grados de coordinación para realizar acciones de gran alcance y sostenerlas en el tiempo.

Por otra parte, las diferencias en los ritmos e impactos de la acción colectiva se explican por interacciones entre las variables estudiadas que promueven cambios en las EOP. La "partidocracia" desincentivó la participación institucional de los movimientos, los cuales, al encontrar costos reducidos para la acción colectiva en términos de los niveles de represión, privilegiaron la protesta disruptiva. Esto llevó a la polarización y la oposición de las élites a las reivindicaciones del movimiento, lo que impidió encontrar aliados para desarrollar reformas institucionales en forma temprana. Paradójicamente, el movimiento indígena perdió su capacidad de movilización luego de participar en el gobierno de Gutiérrez (2003), pues terminó por deslegitimar esa forma de participación y dislocar sus articulaciones con otros actores sociales.

Este análisis permite matizar ciertas asunciones comunes en el estudio de los movimientos sociales. Desde la perspectiva del impacto institucional 
de la acción colectiva, la fuerza de un movimiento social no siempre depende de su cohesión organizativa y discursiva, ni de su capacidad para generar protestas de gran alcance. Así, un movimiento indígena "fuerte" como el ecuatoriano, aunque consiguió altos niveles de articulación organizativa y discursiva, no consiguió reformas orientadas al reconocimiento de sus derechos colectivos en forma temprana. Cuando se produjeron las principales reformas (2008), la capacidad de protesta del movimiento había menguado considerablemente. Así pues, es necesario realizar análisis más matizados de la fortaleza o debilidad de los movimientos enfocando dimensiones como el contexto político y los tipos de repertorios implementados.

De la misma manera, no siempre los Estados represivos inhiben las posibilidades de realización de los objetivos de los movimientos ni los Estados "blandos" los facilitan. Un Estado "blando", en el sentido de menos represivo, como el ecuatoriano mantuvo durante un buen tiempo los canales institucionales cerrados. En estos casos, factores como la apertura de los canales institucionales, el grado de legitimidad del Estado o la forma como los movimientos construyen sus oportunidades pueden tener mayor capacidad explicativa.

\section{Referencias}

Acosta, A. (2005). Ecuador: Ecos de la rebelión de los forajidos. En Nueva Sociedad. No 198, 42-54. Ecuador: Aportes.

Almeida, J. (1993). El levantamiento indígena como momento constitutivo nacional. En VVAA, Sismo étnico en el Ecuador. Varias perspectivas. Quito: Abya Yala-CEDIME, 7-28.

Almeida, J. (1995). Introducción. En Almeida José (Ed.), Identidades indias en el Ecuador contemporáneo. Cayambe: Abya Yala. 5-20.

Barrera, A. (2001). Acción colectiva y crisis política. El movimiento indígena ecuatoriano en la década de los noventa. Quito: OSAL-CIUDAD-Abya Yala.
Beck, S. \& Mijeski, K. (2000). Indígena Self-Identity in Ecuador and the Rejection of mestizaje. Latin American Research Review, 35, (1), pp. 119-137.

Bengoa, J. (2000). La emergencia indígena en América Latina. Santiago de Chile: FCE.

Bretón, V. (2003). Desarrollo rural y etnicidad en las tierras altas de Ecuador. En Bretón Víctor y García Francisco (Eds.), Estado, etnicidad y movimientos sociales en América Latina. Ecuador en crisis. Barcelona: Icaria. 217-253.

Chancoso, B. (1993). Damos la cara. En Cornejo Penacho, Diego (Ed.), Los indios y el Estado país. Pluriculturalidad y multietnicidad en el Ecuador. Contribuciones al debate. Quito: Abya Yala. 135151.

Chiriboga, M. (1986). Formas tradicionales de organización social y actividad económica en el medio indígena. VVAA. 1986. Del indigenismo a las organizaciones indígenas. S.I. Abya Yala. 29-90.

CONAIE. (1989). Las nacionalidades indígenas en el Ecuador. Nuestro proceso organizativo. Segunda edición revisada y aumentada. Quito: Ediciones Tincui-CONAIE.

Dávalos, P. (2005). De paja de páramo sembraremos al mundo. Izquierda, utopía y movimiento indígena en Ecuador. En Rodríguez, César. et al. (Eds.), La nueva izquierda en América Latina. Sus orígenes y trayectoria futura. Bogotá, Colombia: Norma. 354-403.

Della, D. (1999). Movimientos sociales y Estado: algunas ideas en torno a la represión policial de la protesta. En McAdam, D., McCarthy, J., y Zald, N. Movimientos sociales: perspectivas comparadas. Oportunidades políticas, estructuras de movilización y marcos interpretativos culturales. Madrid: Istmo. 100-142.

Figueroa, J. (1996). Las comunidades indígenas: artefactos de construcción de la identidad étnica en los conflictos políticos del Ecuador contemporáneo. Revista Colombiana de Antropología. V. XXXIII. 185-219.

Freidenberg, F. y Alcántara, M. (2001). Los dueños del poder. Los partidos políticos en Ecuador (19782000). Quito: FLACSO.

Gnerre, M. y Botasso, J. (1986). Del indigenismo a las organizaciones indígenas. En VVAA. Del indigenismo a las organizaciones indígenas. S.I. Abya Yala. 7-27.

Gros, Ch. (1999). Ser diferente por (para) ser moderno o las paradojas de la identidad. Algunas reflexiones sobre la construcción de una nueva frontera étnica en América Latina. En Análisis Político. No. 36 enero- abril. 3-20.

Gros, Ch. (2000). De la nación mestiza a la nación plural: el nuevo discurso de las identidades en el contexto de la globalización. En Sánchez Gonzalo y Wills María Emma (Comps.). Museo, memoria y nación. Misión de los museos nacionales para los ciudadanos del futuro. Bogotá, Colombia: ICANH-IEPRI-Ministerio de Cultura. 351-363. 
Guerrero, F. y Ospina P. (2003). El poder de la comunidad. Ajuste estructural y movimiento indígena en los andes ecuatorianos. Buenos Aires: Clacso.

Ibarra, A. (1992). Los indígenas y el Estado en el Ecuador. Quito: Abya Yala.

Ibarra, H. (1999). Intelectuales indígenas, neoindigenismo e indianismo en el Ecuador. Ecuador Debate. No 48, diciembre. 71-94.

Ibarra, H. (1999). Intelectuales indígenas, neoindigenismo e indianismo en el Ecuador. Ecuador Debate. No 48, diciembre. 71-94.

Iglesias, P. y Espasandín, J. (2007). Introducción. La globalización y los movimientos sociales bolivianos. En Iglesias, P. y Espasandín, J. (Coords.). Bolivia en movimiento. Acción colectiva y poder político. España: EI Viejo Topo. 29-65

Korovkin, T. (2002). Comunidades indígenas, economía de mercado y democracia en los andes ecuatorianos. Quito: CEDIME-IFEA-Abya Yala.

León, J. (1994). De campesinos a ciudadanos diferentes. El levantamiento indígena. Quito: CEDIME-Abya Yala.

León, J. (2005). Los pueblos indígenas y su participación gubernamental en Ecuador 2002-2003. En León, Jorge (Ed.) Participación política, democracia y movimientos indígenas en los Andes. La Paz: IFEAEmbajada de Francia en Bolivia-PIEB.

Macas, L. (2005). La necesidad política de una reconstrucción epistémica de los saberes ancestrales. En: Dávalos, Pablo (comp): Pueblos indígenas, Estado y democracia Buenos Aires: CLACSO.

Massal, J. (2000). Movimientos sociales, democratización y multiculturalismo. En Massal Julie y Bonilla Marcelo (Eds.), Los movimientos sociales en las democracias andinas. Quito: FLACSO-IFEA. 157-192.

Massal, J. (2006). La reforma política en Ecuador en un callejón sin salida. Análisis Político. No. 56, eneroabril. 132-150.

McAdam D. (1999). Orígenes terminológicos, problemas actuales, futuras líneas de investigación. En McAdam, D., McCarthy, D. y Zald, N., Movimientos sociales: perspectivas comparadas. Oportunidades políticas, estructuras de movilización y marcos interpretativos culturales. Madrid: Istmo. 49-70.

McAdam D., McCarthy, J. y Zald, M. (1999). Oportunidades, estructuras de movilización y procesos enmarcadores: hacia una perspectiva sintética y comparada de los movimientos sociales. En McAdam, D., McCarthy, J. y Zald Mayer N. Movimientos sociales: perspectivas comparadas. Oportunidades políticas, estructuras de movilización y marcos interpretativos culturales. Madrid: Istmo. 21-46.
McAdam, D., Tarrow, S. y Tilly, Ch. (2005). Dinámica de la contienda política. Barcelona: Hacer.

McCarthy, J. (1999). Adoptar, adaptar e inventar límites y oportunidades. En McAdam, D., McCarthy, D., y Zald, N., Movimientos sociales: perspectivas comparadas. Oportunidades políticas, estructuras de movilización y marcos interpretativos culturales. Madrid, Istmo. 205-220.

Moreano, A. (1993). El movimiento indio y el Estado multinacional. En Cornejo, Diego. (Ed.), Los indios y el Estado país. Pluriculturalidad y multietnicidad en el Ecuador. Contribuciones al debate. Quito: Abya Yala. 215-156.

Moreano, A. (2006). Ecuador en la encrucijada. OSAL. No 19, enero -abril. 65- 74.

Moreno, S. y Figueroa, J. (1992). El levantamiento del Inti Raymi de 1990. Quito: FESO-Abya Yala.

Ruch, D. (1999). El impacto de los contextos nacionales sobre la estructura de los movimientos sociales: un estudio comparado transnacional y entre movimientos. En McAdam, D., McCarthy, D. Y Zald, N. Movimientos sociales: perspectivas comparadas. Oportunidades políticas, estructuras de movilización y marcos interpretativos culturales. Madrid: Istmo. 262-287.

Sánchez, J. (1996). Población y pobreza indígenas. Quito: CAAP.

Snow, D. y Benford, R. (1992). Master frames and cycles of protest. En Morris, D. y McClury, Carol. Frontiers in social movement theory. New Haven and London: Yale University Press. 133-155.

Tarrow, S. (1997). El poder en movimiento. Los movimientos sociales, la acción colectiva y la política. Madrid: Alianza.

Tarrow, S (1999). Estado y oportunidades: Ia estructuración política de los movimientos sociales. En McAdam, D., McCarthy, D. y Zald, N., Movimientos sociales: perspectivas comparadas. Oportunidades políticas, estructuras de movilización y marcos interpretativos culturales. Madrid: Istmo. 71-99.

Yashar, D. (2005). Contesting Citizenship in Latin America. The rise of Indigenous Movements and the Posliberal Challenge. New York: Cambridge University Press.

Zald M. (1999). Cultura, ideología y creación de marcos estratégicos. En McAdam, D., McCarthy, D. Y Zald, N., Movimientos sociales: perspectivas comparadas. Oportunidades políticas, estructuras de movilización y marcos interpretativos culturales. Madrid: Istmo. 369-388. 